\title{
La primera etapa del andalucismo
}

\author{
josé Manuel Cuenca Toribio
}

\section{LOS ORIGENES DEL REGIONALISMO ANDALUZ. LA JUNTA DE ANDÚJAR}

La mixtificación del pasado que en la actualidad, como en cualquier presente español de la Edad Contemporánea, se practica por doquier, ha determinado que las corrientes regionalistas andaluzas se dibujen con unas proporciones nunca tenidas en la realidad. Los brotes regionalistas aparecidos en los últimos años de reinado de Isabel II en minoritarios círculos intelectuales de una o dos capitales del mediodía peninsular tuvieron bien poco de reivindicativo o creador, limitándose a una ponderada queja de la desatención surgida por el sur en una Corte pletórica de andaluces, así como una exaltación, más mimética que espontánea, de los incontables valores de las más extensas comarcas del país.

Menos vigor aún tuvo el sentimiento andalucista atribuido a los junteros iliturgitanos de 1835. En realidad, lo que algunos publicistas consideran el jalón miliar del regionalismo andaluz contemporáneo es más una categoría novelística que historiográfica (algún notable psiquiatra metido en sus vigilias a historiador por afición introduce en la escena a ilas "masas andaluzas" ebrias de autonomía y federalismo...!). La Junta formada en Andújar en las primeras horas del septiembre de dicho año e integrada por dos miembros de las ocho flamantes provincias andaluzas no fue otra cosa sino un eslabón más de la fronda progresista levantada contra el moderantismo del primer ministro Conde de Toreno, rechazado frontalmente por los sectores que se consideraban los herederos natos del doceañismo para acabar con el carlismo y consolidar a un balbuciente todavía régimen constitucional'.

¿Se puede considerar la Junta Central de Andújar como el inicio de una conciencia andaluza?... Ciertamente, el regionalismo surge en España con fuerza a partir del último tercio del siglo $x \mid x$, y en regiones de la periferia conscientes de su peculiaridad histórica, lo que no sucede en Andaluciá, donde aún hoy, en vísperas de poseer un Estatuto de Autonomía, tiene poco 
Los ensayistas que cantan sin acribia alguna el nacimiento del andalucismo en un organismo compuesto por aristócratas turbulentos y burgueses oportunistas siguen dócilmente, horros de documentación -no existen las Actas capitulares relativas a tal período-, la versión muy interesada de don Francisco Pi y Margall sobre dichos acontecimientos, tergiversados 0 , más exactamente, abultados, por su pluma para apoyar sus conocidas tesis acerca del principio de las nacionalidades y la estructura federal de base sinolagmática deseada por el honesto político catalán como clave palintocrática de todos los males de la patria ${ }^{2}$.

\section{EL ANDALUCISMO DURANTE EL SEXENIO DEMOCRÁTICO}

La "Gloriosa" dio vado a una corriente más anchurosa socialmente con la incorporación de algunos núcleos políticos avanzados: pero sin que el movimiento progresara en cuanto a profundización intelectual ni desembocase nunca en un cuerpo de doctrina como pronto iba a ofrecer el

arraigo el regionalismo [... sin embargo] cen la coyuntura de 1835 pueden observarse, aunque desdibujadas e imprecisas, unas alternativas a nivel regional-federal. No tenemos fuentes precisas para verificarlo, pero la propia existencia de tal Junta como asamblea de representantes de la Federación de Andalucías es un dato muy significativo y a tener en cuenta", concluye un ponderado y concienzudo autor con palabras que admiten la discrepancia. MACHADO, J., "Andújar y el movimiento juntero andaluz de 1835", en Andújar: Arte e historia de una ciudad andaluza. Andújar 1982, 81-82. Otro estudioso nada sospechoso de "antiandaluzismo" se pregunta: "La Junta Soberana de Andújar o las Juntas de Andalucía durante esta primera etapa ¿no deberían más bien enmarcarse en la participación activa o muy activa de la burguesía andaluza en la construcción de un estado nacional y en la revolución burguesa? ARCAS CUBERO, F., "Aspectos de la trayectoria histórica del andalucismo", en Nacionalismo y regionalismo en España (El horizonte politico-institucional, económico, social, cultural e internacional de nuestro tiempo). Córdoba 1985, 91. Sin prueba alguna afirma Gómez Martínez, E., en su, por lo demás, muy aprovechable Aproximación a la historia de Andújar: "Para coordinar la acción de las Juntas Provinciales andaluzas se crea la Junta Suprema Central de las Andalucias, con sede en Andújar, que constituyó un primer momento de política unitaria en Andalucía". Andújar 1989, 73 $Y$ por su parte un destacado administrativista interesado por la historia de su región aventura: "La Junta Suprema de Andalucia de 1835 constituye un importante, aunque fugaz, movimiento en el que se recupera la unidad de Andalucia, con objetivos importantes, pero que, al menos para no pocos de sus componentes, más parecían ser coyunturales que estables y duraderos. Cuando se intenta la permanencia de la Junta, se produce la división entre las Juntas Provinciales y las discrepancias entre algunas de éstas y la Suprema de Andújar. En esas tensiones triunfó la división sobre la unidad y Andalucía volvió a desintegrarse en la Diputaciones Provinciales de acuerdo con los deseos del Gobierno de la nación". Clavero Arévalo, M., El ser andaluz. Madrid 1984, 89.

2 Del gobierno "del hombre audaz, de corazón cieno", cuya autoridad apenas si sobrepasaba la estancia en que celebraban sus reuniones, llegaría a afirmar en su obra Las nacionalidades: "... tuvieron las de Andalucía su Junta Central de Andújar y hablaron de potencia a potencia con el gobierno de Cristinam, 215. 
ejemplo catalán, con una triple formulación ideológica de su regionalismo, convertida en alguna de ella en verdadero nacionalismo.

Ello iba a ponerse de relieve de manera indubitable en un episodio de gran relevancia en el caminar del regionalismo andaluz: el pacto de Córdoba de 1869. Confundidas las aguas del regionalismo con las del republicanismo por la debilidad ideológica del primero y la identidad de los protagonistas y abanderados de uno y otro, era lógico que el andalucismo fuese a remolque del republicanismo, cuyas esencias, sin embargo, no estaban aún por completo decantadas y formulaciones y planteamientos se hallaban sometidos a un empeñado debate entre sus adeptos.

Importado en gran medida de Cataluña, patria espiritual del primer republicanismo hispano, los representantes de las diferentes provincias andaluzas eligieron la opción histórica de la organización del Estado para la formulación de un poder político andaluz al cual vinieran a unirse las tierras de la Extremadura baja y las murcianas, para formar así una constelación administrativo-política. El sentimiento de la especificidad andaluza estaba, empero, muy poco resaltado y, sobre todo, sometido a los vaivenes tácticos de las dos posiciones enfrentadas en Córdoba. De manera bastante parecida a lo que sucediera en Andújar treinta años atrás, el establecimiento de un programa mínimo fue difícil y logrado de manera pírrica. La carencia de una vibración singularizada de lo andaluz volvió a revelarse días después cuando el poderoso federalismo municipalista de algunas ciudades andaluzas —en particular, Sevilla y Cádiz - rechazaba los acuerdos de los notables republicanos congregados, sin demasiada armonía, en la antigua capital del califato ${ }^{3}$.

\section{REGIONALISMO, REPUBLICANISMO Y MASONERIAA}

Con todo, para bien y para mal, los destinos del regionalismo andaluz del último tercio del ochocientos estaban unidos a los del republicanismo. Incluso sus líderes más autónomos no cesaron nunca de proclamarlo.

Pero también otra fuerza estuvo indisociablemente unida al decurso del regionalismo meridional. En medida superior al catalanismo y, naturalmente, al nacionalismo vasco — de raiz y cepa ranciamente clericales-, la masonería jugó hasta 1936 un destacado papel en la evolución del

\footnotetext{
${ }^{3}$ Vid. el denso artículo de ARIAS CASTAÑ́N, E., "Notas para el estudio del republicanismo andaluz en el siglo xix: El Pacto Federal de Córdoba (1869)", Archivo Hispalense 220 (1989), en especial 58-62.
} 
andalucismo. Obviamente, no hay que ver en ello ninguna ridícula conspiración de la "antiespaña" ni de los elementos heterodoxos de la tradición nacional para destruir la unidad de la patria... En la coyuntura del Sexenio, como con anterioridad y con posterioridad en las fases más ebullentes de nuestra historia contemporánea, el triple haz de fuerzas mencionado hacia siempre converger sus energías para orear la vida española con los vientos de la democracia y el cambio, bien que el anticlericalismo - uno de sus elementos unificadores, salvo en el caso de los nacionalismos históricos- no pasase, en ocasiones, de ser una coartada del conservadurismo más recalcitrante ${ }^{4}$.

De importancia fácil de imaginar, sería conocer si esta protagonismo absorbente de los llamados «librepensadores" por los ultramontanos impidió que la clerecía andaluza jugara ni siquiera un mínimo papel en la conformación del llamado andalucismo histórico --no así en el posterior-; o si, por el contrario, fue la ausencia y distanciamiento de un sacerdocio autóctono, muy poco culto e interesado por las opciones regionales, lo que hizo que tanto en Andalucía como en Extremadura su sentimiento nacionalista se encauzase y dirigiese por los elementos progresistas ${ }^{5}$.

En todo caso, el que el andalucismo fuera un movimiento del que estuvieron permanentemente ausentes tanto los curas como los capitalistas, muy activos unos y otros en estas décadas finales del $x \mathrm{x} x$ y en las del comienzo del $x x$ en el catalanismo y el vasquismo, ${ }^{6}$ determinó un

${ }^{4}$ Es muy esclarecedor al respecto el documentado trabajo de ARIAS CASTAÑón, E. y EnRIQuez DEL ÁRBOL, E., "Masonería y política en la Sevilla del sexenio democrático (1868-1874)", en Masonería, Politica y Sociedad. Zaragoza, I, 1989, 35 y ss., en particular 44 y 50-51.

'Cuenca ToRibio, J. M., «Un posible punto de partida para el análisis de una cuestión clave de la historia española contemporánea: El anticlericalismo", en Masoneria... 11, 709-730.

${ }^{6}$ Con proyección especialmente a los acontecimientos de nuestros días, será tal vez esclarecedor el siguiente texto: "La influencia de la Iglesia en el País Vasco es un hecho tan evidente que se constata en todas las esferas, desde la vida política hasta la cultura. La multiplicidad de corrientes y de formas de manifestarse permite hablar de las "iglesias" en el País Vasco, aunque todas sean católicas, apostólicas y más o menos romanas. Los laicos son una especie poco común en Euskadi. La clase politica ha pasado por los seminarios, los intelectuales han pasado por los seminarios, los periodistas han pasado por los seminarios... La iglesia en Euskadi es un poder fáctico y multiforme... Sin embargo, algo tan obvio no fue reseñado por nadie, y quizá la razón hay que buscarla en el tabú que constituye hablar de la Iglesia católica y de su influencia en un país donde hay un sacerdote para todo... En el clero vasco caben todas las opciones dentro del nacionalismo, y este hecho tiene unos componentes sociales de largo alcance, algunos de los cuales penetran en el fundamentalismo abertzale. Es decir, hablando en plata, el que una parte del clero vasco avale e incluso propugne la violencia política para convertirse en religiosa: aunque pierda este reino y muera, ganará el de los cielos. Pero el clero vasco no es mayoritariamente "abertzale" sino "nacionalista"; más radical en Guipúzcoa, más moderado en Álava.

La cultura vasca tradicional rezuma elementos religiosos por todos sus poros. El mundo de la religión, con sus dogmas y sus fes inquebrantables, no se puede separar de muchos de los 
rasgo esencial de aquél, estableciendo una de sus principales diferencias, si no la más importante, con las restantes corrientes de igual índole, incluida la gallega, la valenciana y hasta la aragonesa... Este laicismo a ultranza le revistió de caracteres de modernidad, aunque la falta de mecenazgos culturales y caución eclesiásticos impidiera la profundización en su teoría y limitara ampliamente su difusión.

Los pueblos, como las grandes instituciones y fuerzas sociales y políticas, recogen sus principales caracteres en los inicios de su andadura. El andalucismo no quebró, desde luego, dicha pauta, y así, a diferencia igualmente del nacionalismo vasco y catalán, algunos de sus ideólogos e impulsores de la primera hora nacieron lejos de Andalucía, aunque probarian con hechos y obras su gran amor hacia ella. El ejemplo del madrileño Joaquín Guichot, también republicano - muy acomodaticio...- y masón, autor con su Historia general de Andalucía, como es bien sabido, de la biblia historiográfica del movimiento, comparece para dar alto testimonio de lo antedicho.

Republicanos, masones y andalucistas se reclutaban por lo general en la misma cantera social e ideológica a fines del $x \mid x$ y comienzos del $x x$. A pesar de que al igual que en el resto del país el consolidamiento y la importancia, tanto cuantitativa como cualitativa, de la masonería andaluza no debe en forma alguna magnificarse sino más bien al contrario, es incuestionable que a su élite ideológica y social le correspondió timonear este triple frente oposicionista —en realidad, insistamos, reducido, en la práctica, a uno solo ${ }^{7}$.

conceptos en los que se mueve la violencia y es la base sobre la que muchos se sienten seguros a la hora de considerar la diferencia entre un ajusticiamiento y un asesinato... De esto no se deduce que la violencia partiera de ahí, sino que el contexto represivo de la dictadura facilitó la explosión de la radicalidad al unir sentimiento nacional oprimido con verdades trascendentes religiosas.

Así llegamos al punto clave para entender un segmento importante de la crisis intelectual y cultural del Pais Vasco; la ausencia del laicismo liberal." MoRÁN, G., Testamento vasco. Un ensayo de interpretación. Madrid 1988, 158-160.

El siguiente texto nos da clara idea de la inmensa distancia entre catalanismo y andalucismo. En Cataluña cualquier corriente o fuerza debía supeditarse a su triunfo; en Andalucia sucedia al contrario, convirtiéndose en su motor artificial cualquier tendencia a un movimiento: "Sabido es que la recuperación económica de los siglos XVII y XVIII, la consolidación del proyecto burgués y el renacimiento cultural del siglo $x \mid x$ cristalizaron en la formulación del catalanismo como elementos de cohesión política y social. No obstante, no significa ello que el catalanismo fuera patrimonio exclusivo de la burguesia, sino por el contrario éste habia asumido elementos de la cultura popular que, en la línea del romanticismo alemán, venían a dar contenido a las reivindicaciones nacionales. De tal suerte que el catalanismo se convirtió - ultrapasando el sueño romántico - en amplia canalización de la inquietud social, asumiendo las diversas ideologías y manifestándose a través de diversos canales sociales [...] Por tanto, cualquier elemento u organismo político, o social, o cultural, o religioso, a la larga - si vivía realmente inmerso en 
Muchos son los ejemplos que acuden al recuerdo para refrendar esta hipótesis, pero, para ajustarnos al período que suscita esta consideración, ninguno tan significativo como el de Francisco María Tubino. Director del mejor y más influyente diario de todo el sur -incluido aquí el territorio de la Baja Extremadura - La Andalucía, aparecido en 1858. Este personaje, más inconsistente ideológicamente de lo descrito por alguno de sus estudiosos recientes, estuvo durante décadas en el centro de todas las operaciones y actividades desplegadas para el triunfo, por medios pacificos, de una república progresista y federal, sin preocuparse en exceso de las debilidades y contradicciones que su paisano, el integrista cura gaditano Francisco Mateos Gago, ponía al descubierto con la vis polémica y la sal gorda características de la mayor parte de nuestros escritores ultramontanos ${ }^{8}$.

Respecto a otra de las claves para una interpretación adecuada y conforme a la realidad de los hechos de los orígenes del andalucismo y del papel representado en sus avatares decimonónicos, existen muchos extremos previos que aclarar -en especial, la reconstrucción de toda la corriente republicana andaluza y la propia visión de Andalucía en los políticos autóctonos - antes de llegar a clarificaciones en la polémica suscitada entre ciertos estudiosos sobre si el pensamiento federalista de algunos miembros del grupúsculo teórico del andalucismo finisecular privó a éste de convertirse en un verdadero nacionalismo, a semejanza del vasco y, en particular, del catalán ${ }^{9}$.

El protagonismo y la propia tipificación e identidad de la intelectualidad burguesa progresista en la conformación de un sentimiento a través del cual podía conectar con las capas populares y, sobre todo, con los es-

la realidad del país - acababa invadido por el cúmulo de circunstancias que permitieron a los catalanes formular su hecho diferencial en la clave de modernidad, nunca como un proyecto únicamente arqueológico [...] En efecto, la francmasonería mantuvo respecto del catalanismo una actitud similar a la del resto de organizaciones enraizadas en la realidad catalana. Es decir, los indicatos, las organizaciones patronales y económicas, culturales, la enseñanza, los medios de comunicación, etc. [...] De lo que resulta la existencia de la convicción que cualquier organización que quiso subsistir en la Cataluña del último tercio del siglo xix, tuvo que asumir dicho proceso, y por tanto pasar inevitablemente por un período de crisis interna [...] Por tanto, el estudio de la masoneria en Cataluña debe asentarse sobre el conocimiento de las relaciones de aquélla con el hecho diferencial." Olive Serret, E., "Catalanismo y masonería. Bases para su estudio", en La masonería en la España del siglo xix II. Valladolid 1987, 467-468.

${ }^{8}$ Cfr. en particular Colección de opúsculos III. Sevilla 1887, 230. Su filiación masónica la acredita FERRER BENIMELI, J. A., en "El Grande Oriente Lusitano Unido y los masones españoles (1869-1878)", Ibidem, 500.

${ }^{9}$ Recientemente, un equipo del área de Historia Contemporánea de la Universidad de Córdoba ha emprendido el estudio del concepto y la imagen de Andalucía reflejada en la intervención de sus parlamentarios decimonónicos. 
tratos medios para afianzar su liderazgo, es otro de los puntos en que no se ha profundizado como el tema de los orígenes del andalucismo lo requiere. En fin, hoy por hoy, apenas si puede irse más allá de afirmar que la intimidación sufrida por la burguesía andaluza ante el movimiento cantonalista alicortó sus vuelos políticos y redujo su papel al de espectadora o comparsa del caciquismo restaurador ${ }^{10}$.

Numéricamente, Andalucía fue uno de los enclaves de entidad del republicanismo hispano, arraigado con firmeza en zonas con mayor predominio urbano que el sur, como Cataluña y Valencia. Dicha importancia cuantitativa no se vio acompañada, empero, de formas especificas ni considerables de influencia, hegemonía u orientación nacionales, cabiendo al republicanismo andaluz un papel satelizador en el panorama republicano hispano, sobre todo a fines de siglo cuando nuevas corrientes afloraron con fuerza dentro de tal movimiento, plasmándose en agrupaciones como la blasquista. Esta anemia ideológica tuvo un momento de máxima expresión al desperdiciar una muy favorable ocasión para ver convertido al republicanismo andaluz en motor del español y en fermento regenerador de la caciquil y deturpada vida política andaluza. En 1883, el Congreso - Asamblea regional de Antequera (27-29 de octubre) significaba el desaprovechamiento de una oportunidad de oro para fundir burguesía y pueblo en el logro de un regionalismo alimentado por savia republicana.

Objeto de disputa entre los analistas de los orígenes del regionalismo meridional, dos tesis se enfrentan esencialmente a la hora de interpretar la verdadera entraña del texto -en realidad, tres proyectos constitucionales: Municipio, Cantón y Federación, aunque sólo se tratara, al menos en las sesiones públicas, del último- que redactara el diputado republicano por Alora Carlos de Saornil —si bien existen algunas dudas sobre su verdadera paternidad, atribuida algunas veces a un equipo anónimo. Según unos estudiosos su diseño de Andalucía no guardaba consonancia alguna con su realidad socioeconómica y se limitaba al mero calco del programa establecido para las diversas comunidades de España por el ya mencionado Congreso Republicano de Zaragoza tenido en aquel mismo año de $1883^{11}$.

\footnotetext{
10 "Estamos, pues, ante un "reionalismo" que es más una voluntad y un impulso, que un proyecto estructurado. Real, pero inorgánico, aparece y desaparece de acuerdo con los peculiares perfiles de la coyuntura. Existe como sentimiento y como vocación... e, incluso, como propuesta sectorial y específica. Pero como proceso amplio y continuo que se afianza y afirma. Determinadas capas sociales lo "viven", más que lo ejercen, y, desde esta vivencia lo transmitirán como alternativa de futuro que otros, años después, recogerán." LAComBA, J. A., Regionalismo y autonomia en la Andalucia contemporánea (1835-1936). Granada 1988, 62

"A dicha Asamblea de Zaragoza asistieron algunos andaluces, miembros del Partido Re-
} 
Otros investigadores defienden su gran virtualidad para el futuro de la región, a la que el texto presentado y aprobado en el congreso antequerano ofrecía toda una opción de gobierno y un detallado marco jurídicopolítico para plasmar sin distorsiones ni violencias una nueva sociedad, según el modelo regeneracionista de esencias y raíces, en última instancia, krausistas, que alentaban en el credo republicano, singularmente, en el de corte pimargalliano $-\mathrm{y}$ en su expresión política, el Partido Demócrata Republicano Federal ${ }^{12}$.

Con una de esas acrobacias mentales exigida por la construcción en el vacío que impone el sueño de un nacionalismo sin nacionalistas, se ha

publicano Federal, quienes elaboraron un "proyecto de Constitución" que, en esencia y en la letra, no era sino una vulgar transcripción del Proyecto General de Constitución Federal, a nivel del Estado, sin fundamentación especifica alguna referida al caso de Andalucia e igual, por tanto, a las restantes que se elaboraron para las otras regiones, pues lo que varía tan sólo es el nombre de la región a la que se aplica. Se limita a enunciar una serie de principios, derechos y libertades fundamentales de todo Estado democrático sin que aparezca por ningún lugar referencia alguna, explícita o implícita, a la realidad andaluza. Ya esta simple transcripción de un mero proyecto de Constitución federal es a lo que se ha pretendido hacer pasar como primer proyecto histórico de la autonomia andaluza, sin que haya constancia de que fuera redactado por andaluces y, menos aún, conocido en Andalucía fuera del reducido cenáculo del Comité republicano federal." Bernal, A. M., Historia de Andalucia VIII. Barcelona 1982, 40.

12 Desde una posición monroista, muy peligrosa por sus efectos de boomerang, un constitucionalista andaluz es tal vez el principal valedor de tal tesis, Acosta SÁnCHEz, J., La Constitución de Antequera. Estudio teórico-crítico. Democracia, federalismo y andalucismo en la España contemporánea: "No estamos desde luego ante una falsa cuestión... Lo que cabe reprochar el señor Bernal no es, por tanto, que esgrima la supuesta contradicción para atacar la concepción de Blas Infante y los resultados de su modesto - pero progresivo e históricomovimiento nacionalista, sino que lo haya hecho de forma tan superficial y apresurada, es decir, sin llegar al fondo del problema y sin demostrar conocimiento de los términos del debate; acaso y en buena parte porque, debido a su especialidad, o esté familiarizado con unos temas que son político-ideológicos y tienen importantes vertientes jurídicas y constitucionales. Lo que queremos decir es que la valiosa aportación del citado profesor a la historia económica y social de Andalucía no le garantiza, por sí misma, la entrada en otras áreas de la historia andaluza, tales como la problemática federal y la regionalista/nacionalista, con un cierto rigor." Sevilla 1983, 22-23. Un poco salomónicamente un gran abogado y administrativista enjuicia así la que para algunos estudiosos vendría a ser la "Carta Magna" del andalucismo: "La valoración que hay que hacer de este documento de un partido político y en modo alguno la expresión de una Asamblea oficial de fuerzas políticas. En segundo lugar, que la viabilidad del mismo hubiera requerido una modificación constitucional ya que en modo alguno tenía encaje en la entonces vigente que era la de 1876. En tercer lugar que resultaba difícil juzgar política y técnicamente un documento fuera del momento histórico en que se produce, pero en cualquier caso no puede dejar de indicarse que, además de lo dicho, tiene no poco de utópico y que con el, dad la configuración de los poderes andaluces que se determinan, la gobernabilidad de Andalucía no hubiera sido fácil. Finalmente, la falta de vinculación expresa de Andalucía con España, ofrecida sólo como posibilidad no obligatoria, hubiera merecido el rechazo de la mayoría de los andaluces. Tiene, sin embargo, este documento el mérito de ser el primer Estatuto sobre la autonomía de Andalucía de que tenemos noticia." Clavero Arévalo, M., El ser andaluz. Madrid 1984, 91. 
llegado a afirmar que los asambleistas de Antequera realizaban la perfecta síntesis del pensamiento proudhoniano al empalmar, desde un irrenunciable republicanismo, con la versión más radical del ideario proudhonista $y$, por ende, con el campesinado andaluz galvanizado por el credo bakuninista, tributario un tanto malgré lui del autor de La propiedad es un robo. Como ejercicio de profundización en la historia de las ideas políticas de la España contemporánea, tal exégesis es perfectamente legítima, aunque sin sustancia historiográfica alguna, ya que ni antes, ni entonces, ni después se ha podido encontrar documento o escrito alguno que demuestre la adhesión — ni siquiera la sintonía - de la militancia anarquista sureña con los planteamientos del andalucismo.

Sin terciar en estas páginas y aún menos dar por resuelta una cuestión sin duda enrevesada y asaz problemática resulta difícil sustraerse a la idea de la frustración del republicanismo como motor del cambio que Andalucía demandaba con imperiosidad. Esta falta de liderazgo quebró cualquier posibilidad a corto plazo de convertirse en el cauce de expresión de un sentimiento regional muy minoritario y a la búsqueda anhelante de un ideario vertebrado y sólido capaz de transformarse electoralmente en una fuerza realmente movilizadora.

Utopismo y ucronismo se confabularon para dejar sin un auténtico programa a un regionalismo con atracción política, social y cultural.

El regionalismo que superficialmente aceptara en la experiencia anterior, quedó por completo olvidado, desempolvándolo, en ocasiones, como cobertura de la oposición al régimen de Sagunto. Mientras que en el País Vasco y, sobre todo, en Cataluña, el nacionalismo hallaba su soporte y nervio en una estrecha franja de la burguesía, conformando al de Euskadi, en el tiempo récord de una década, en Andalucia su deserción de una bandera, asumida otrora sin demasiada convicción, sería completa. A lo largo de la primera década del siglo $\mathrm{xx}$, el regionalismo de algunos intelectuales cuajó en fórmulas políticas presentadas como los últimos ecos del regeneracionismo costista, en confusa amalgama de recetas palingenésicas, expresadas a través de una retórica anticanovista en la que la paja - confusión, ambigüedad-prevalecía sobre el grano - poder tentacular del caciquismo, decrepitud del bipartidismo gobernante - para quedar finalmente estancada en una requisitoria del sistema, que nunca llegó a conmoverse ni en sus esferas madrileñas ni andaluzas ${ }^{13}$.

Aunque había sido ya un extremo señalado por nosotros a mediados de los años setenta, ha estudiado el tema con más detenimiento y agudeza MAURICE, J., «El costismo de Blas infante", en El legado de Costa. Zaragoza 1984, 215-224. Noblemente su mismo colega malagueño había reconocido la profundidad de tal ascendiente en su trabajo La obra de Costa. Sevilla 1916, reproducida parcialmente en Antología de textos. Sevilla 1983, 205-209. 


\section{LA APARICIÓN DE BLAS INFANTE}

En la coyuntura antedicha, en la Sevilla de los primeros años del novecientos, el andalucismo va a cobrar por vez primera verdadera figura histórica en la personalidad de un joven notario malagueño que desgrana diariamente en la tribuna del Ateneo hispalense y en las páginas de la prensa local el dolido diagnóstico que corroe a la Andalucía de los umbrales del siglo $x x$, en particular la injusticia y opresión padecidas por su campesinado.

Elaborado en esencia por Blas Infante (1885-1936) en la estela de los pujantes nacionalismos vasco-catalán, el discurso del andalucismo adoleció, como reiteradamente hemos expuesto en otras páginas, del mimetismo que guió todo el simplista análisis del bienintencionado notario malagueño. A falta de una lengua propia, de una cultura específica y de un pueblo militante, sería una historia mitificada la que sustituiría en su abracadabrante pensamiento a dichos elementos como fundente de una nación andaluza, sólo real en su romántico ensueño ${ }^{14}$.

Éste fue tan tesonero que lograría con materiales averiados y falsas piezas edificar una imagen de Andalucía provista de un perfil que la asemejara a primera vista con el de otras nacionalidades: bandera, himno, reivindicación político-social; y, por último, de una interpretación históricocultural. Su hazaña culminaría con la adhesión entusiasta de un reducido y fiel círculo de partidarios penetrados en su mayor parte de una conmovedora pasión por su tierra natal, sultana vestida de andrajos.

Al amparo de la eclosión nacionalista suscitada por las famosas tesis wilsonianas, el movimiento abanderado por Blas Infante pareció por un momento en la agonía del sistema de la Restauración que iba a poder emparentarse, bien que lejanamente, con el catalanismo y el vasquismo. El Congreso de Ronda -26-28 de marzo de 1918: bandera, escudo e himno andaluces-; y, en especial, la llamada Asamblea Andalucista de Córdoba -14-16 de mayo de 1919- marcaron la hora de máxima euforia y esperanza ${ }^{15}$.

Era el remate de un camino iniciado, como ya vimos, una década atrás. En efecto, con clara imitación del ejemplo catalán las grandes instituciones culturales burguesas celebraban Juegos Florales desde fines del siglo XIX, entre los que descollaron los del Ateneo hispalense y, dentro de su elenco,

14 Cuenca Tohibio, J. M., Ensayos sobre Andalucia. Córdoba 1991.

${ }^{5}$ Sobre esta segunda "primavera de los pueblos" vid. CuENCA TORIBIO, J. M., Historia de la Segunda Guerra Mundial. Madrid 1989. 
el de 1909. El profesor republicano y masón Mario Méndez Bejarano, volvió a resucitar, con gran flama, la antorcha del lánguido andalucismo ${ }^{16}$.

Pocos años más tarde, la controversia sobre la Mancomunidad catalana y el propósito de los gabinetes liberales de extenderlas a las grandes regiones del país dieron alas en la prensa sevillana a un amplio debate sobre las posibilidades de un autogobierno andaluz ${ }^{17}$.

Alentada desde Sevilla, la chispa del andalucismo no volverá ya a apagarse. A la conferencia de Cambó en el Ateneo hispalense en mayo de 1913 sucederá en el mismo año la celebración del I Congreso Georgista Internacional de Ronda (26-28 de mayo) -animado y puesto en pie por el ingeniero zamorano Antonio Albendin-, con numerosas implicaciones en el terreno del andalucismo más exigente. El que pasaba, como también ya vimos, por la solución urgente y radical de la cuestión agraria, conforme a métodos que displacían a las esferas más conservadoras de un movimiento siempre delicuescente, con abstrusas e impostadas raices, sin ningún o feble fundamento histórico, y proyectado quizás sobre la comunidad española más fuertemente invertebrada como era la meridional.

Caldeada en esta atmósfera saldría a la luz la más conocida de las obras de Infante, bien que ésta distara - y mucho- de convertirse en un éxito editorial. Precisamente para dar a conocer la tesis de El ideal andaluz, el joven notario malagueño se pondría en contacto a fines de 1916 con el núcleo regionalista cordobés, aglutinado en torno al "Centro Andaluz" de dicha ciudad, foco y hogar, como el sevillano y el de otras pocas poblaciones, de las ideas de su credo, que reflejaba en su composición la ambigüedad ideológica que esta corriente tenía en su plasmación andaluza. Un par de terratenientes, una parva gavilla de idealistas miembros de las profesiones liberales junto con algún que otro artesano $e$, incluso, un obrero estaban débilmente unidos por un sentimiento de

\footnotetext{
${ }^{16}$ Acerca de este atrabiliario personaje, espécimen ejemplar del "andalucista madrileño", también masón y republicano asi como autor de obras de erudición y crítica - v.gr. su historia de los afrancesados - muy estimables, es reveladora la reprobación generalizada que recibió de sus coetáneos.

Acerca de su filiación masónica en la Granada de 1890 PINTO MoLina, M., "Composición alfabética de la masoneria granadina a fines del siglo XIX". Anuario de Historia Contemporánea 11 (1984), 489.

17 Cfr. especialmente Braojos, A., “Tres discursos historicistas en la Sevilla del pre-regionalismo (1909)", Archivo Hispalense 220 (1989), 213-229; et etiam "La Ley de Mancomunidades y el regionalismo andaluz"; "La propuesta del El Liberal de Sevilla y su sondeo de opinión (1912)", Actas del II Congreso del Andalucismo Histórico. Sevilla 1987, 737-757.
} 
amor a su región natal, aunque algunos tuvieran su ius locis muy lejos del Mediodía ${ }^{18}$.

De estas esferas surgiría el «Manifiesto» de junio de 1917, que, en realidad, no respondía a los planteamientos más genuinos del andalucismo, pues todos sus esfuerzos se concentraban, en la línea de la fronda parlamentaria encabezada por Cambó, en auspiciar la fórmula de unas Cortes Constituyentes que afrontasen resueltamente las dolencias de la nación, con orientación y propósitos indisimuladamente republicanos ${ }^{19}$. Dentro de una atmósfera política nacional muy ebullente, hay que resaltarlo, todo era al comenzar 1918 confuso, contradictorio y hasta caótico en la marcha de un movimiento regionalista, que en nada semejaba a sus grandes ejemplos, en los que tanto la teoría como la praxis -por aberrante que fuera en ciertos extremos - estuvieron en todo momento nítidamente perfilados ${ }^{20}$.

Sólo la habilidad táctica y el buen manejo de asambleas y comités usufructuados por Eloy Vaquero evitaron que los presagios de desastre para la causa del andalucismo radical y transformador con que se abriera, con muy precaria concurrencia, la ya mencionada Asamblea de Ronda se consumaran, dando, por el contrario, un giro de 180 grados a aquélla, que acabó, incluso, por aceptar una propuesta muy avanzada en orden a la solución del problema agrario - distinción entre título y uso de la propiedad, entre ésta y posesión- ${ }^{21}$. Igualmente, haría suyo, con ciertas

: En una literatura generaimente acrítica y algo fantasiosa resulta muy atópica y convincente la visión dada sobre el regionalismo cordobés por ORTIZ VILLALVA, J., “El republicanismo andalucista en Córdoba", en Aproximación sociológica al anda/ucismo histórico. Córdoba 1990 , 75-95. De interés para la reconstrucción de la atmósfera de las relaciones entre los regionalistas de Sevilia y Córdoba, Solano Márquez, F., Memorias de Córdoba. Córdoba 1985, 55.

19 «Tras la firma, la divulgación y la acción. Acaso no quedó importante periódico de Madrid y demás capitales de provincia que no publicase con todos los honores el manifiesto de los cordobeses. Ningún diario de nuestra ciudad, sin embargo, se dignó en sus columnas acogerlo. iYa lo sabes, historiador quien quiera que seas, que en lo futuro trates de extraer de tan escogida prensa local las verdaderas y fuertes palpitaciones del vivir de Córdoba! En VAQUERO, E., Del drama de Andalucía. Recuerdos de luchas rurales y ciudadanas. Córdoba 1987, 123.

${ }_{20}$ Muy estudiado el catalán, remitimos para el vasco a uno de los mejores libros publicados en España durante el último medio siglo (y por ello, naturalmente, poco conocido) AzAOLA, J. M. El País Vasco. Madrid 1988.

${ }^{21}$ Es muy expresivo comprobar la desatención de VAQUERO, E., hacia los aspectos más ideológicos de la Asamblea, recordando sólo en sus memorias las facetas socioeconómicas de ella. "Las facultades autonómicas de los municipios se encontrarán condicionadas por las limitaciones siguientes: Obligación general del referéndum para los asuntos municipales; cuentas detalladas mensuales de la gestión, por impresos repartidos al vecindario, y discusión de los presupuestos en lugares como la plaza pública, con turnos a los vecinos.

Se promulgará una medida legislativa que implante el principio "la tierra andaluza para el cultivador o edificador" y sancione la absorción por la comunidad de la renta económica o valor social del suelo, con el cual y hasta donde alcance su importe se satisfarán las necesidades 
modificaciones, el texto de Antequera de 1883 y delinearía un muy acabado cuadro de la autonomía andaluza en sus diferentes niveles. Merece subrayarse, por último, su decidida toma de posiciones frente a un tema capital mantenido siempre en la ambigüedad y en la reserva por el andalucismo de todos los tiempos. En Ronda el nacionalismo quedó proclamado sin ambages como la idea fuerza y el objetivo postrero de sus afanes $^{22}$.

\section{LA FRUSTRACIÓN DE UN PROYECTO}

No por ello, sin embargo, el andalucismo perdía sus señas de identidad. Su incoherencia doctrinal seguía intacta, sin que sus líderes más comprometidos supieran a ciencia cierta qué hacer con un nacionalismo que no encontraba el menor eco en las masas. Así vendría a corroborarlo la propia desembocadura de la Asamblea.

Al final todo había quedado, realmente, en tablas. Conservadores y progresistas pensarán que, en el futuro, el eclecticismo y la labilidad del programa aprobado favorezca sus respectivas y antagónicas metas. Para los primeros, un andalucismo sentimental y, en todo caso, administrativocultural, con el fin de que todo quede igual. Para los segundos, un andalucismo que, al ayudar a implantar a la República solucione el tema agrario. $Y$ entre los dos bloques, un soñador para un pueblo: Blas Infante.

públicas. Se respetará rigurosamente a los poseedores actuales la propiedad de los cuitivos y edificaciones en sus tierras, desgravándolas asi como al conjunto de las demás manifestaciones del trabajo y del consumo, en un tanto igual a la cuantía en que por el nuevo medio tributario aumente la hacienda municipal. Se indemnizará a los actuales propietarios con el importe mismo de la renta futura, hecho lo cal, tendrán integramente los municipios como caudal de propios las tierras de sus respectivos términos, sin perjuicio de asegurar a los individuos a quienes legitimamente corresponda, la permanencia de la posesión privada de las mismas." Del drama..., 133.

22 Acaso con énfasis algo desmentido por los hechos uno de los pocos historiadores profesionales que hasta hace escasos años se ocuparon del andalucismo, el valenciano LACOMBA, J. A., ha calificado bien el impacto que la Asamblea de Ronda tuvo para el movimiento blasinfantiano. "Todo viene, pues, a mostrar el enorme significado que para la posterior trayectoria del andalucismo tienen los resultados conseguidos en Ronda. Hasta la Asamblea alli realizada, el movimiento regionalista se despliega a partir de impulsos dispares y un tanto aislados y desordenados: desde dicha Asamblea, hay ya un proyecto de referencia para todos los que están empeñados en esta aventura andaluza. Es claro que, pese a ello, el voluntarismo y la ilusión continúan siendo los motores esenciales de la acción andalucista; pero hay ya un programa - máximo y mínimo-. por todos asumido y que a todos orienta y obliga. Hay ya, en suma, unos medios y unos fines precisos para guiar la tarea de cada dia." Regionalismo $y$ autonomia en la Andalucia contemporánea (1835-1936). Granada 1988, 160-161. Acerca de la simbología andalucista el libro de REPISo, F., Símbolos y derechos andaluces. Sevilla 1980. 
Aunque la Asamblea de Córdoba consumara el cisma entre los andalucistas conservadores y ardientes, también el talento político de Vaquero y la fe iluminada de Blas Infante lograron, in extremis, contener la hemorragia, y hacer de lo que había sido, en realidad, un fracaso una victoria. Sus conclusiones marcan, en apariencia, el punto límite y postrero del acuerdo entre las dos corrientes. A través del expediente de expropiación del valor social de las tierras, junto con el pago de la indemnización expropiatoria en títulos de la Deuda, la reforma agraria era, sobre el papel, un hecho ${ }^{23}$.

Pero, a pesar de quedar todo en palabras, los antagonismos y radicales diferencias entre los principales sectores del andalucismo cordobés así como en el muy débil jiennense y más robusto sevillano, no superaron la crisis. Considerando que los acuerdos de la Asamblea cordobesa habían sido obra de un golpe de mano de sus líderes más audaces y combativos, el conservadurismo andalucista -muy reducido como su opositor- desertó en bloque del movimiento que tenía como jefe moral a Blas Infante, desgarrado al intuir la caución cultural que le prestaban los primeros, pero imantado por la vertiente social del andalucismo ${ }^{24}$.

Las repercusiones de la escisión quedaron muy en sordina en un país que vivía en 1919 uno de los años más difíciles de su existencia contem-

${ }^{23}$ Un excelente conocedor de la Córdoba del período glosa así la información proporcionada -en contraste con el ominoso y significativo silencio de la prensa diaria- la por la famosa revista Andalucía del 23-29 de marzo de 1919. "Finalmente en la Asamblea de Córdoba de marzo de 1919 es donde la toma de decisiones sobre el "tema agrario" se convierte en fundamental en el desarrollo de la misma ya que los asambleistas están divididos entre los representantes por algunos miembros de los Centros Andaluces "... que consagran su alianza con las izquierdas, su carácter francamente revolucionario y su credo georgista..." y los situados en torno a la Asociación Regionalista Andaluza que defienden "... el regionalismo independiente encaminado sólo a la exaltación de Andalucía y que se concreta genéricamente en la amplia fórmula de autonomía regional y municipal...", siendo los portavoces más caracterizados de la primera el cordobés Vaquero y el sevillano Ochoa, apoyados por la plana mayor del andalucismo (Infante, Carrión, Gallego Burín, etc.) y el señor J. Gastalver y F. Castejón de las posiciones más moderadas de la ARA. Para J. Gastalver, la cuestión agraria es únicamente de carácter productivista y los regionalistas deben acometerla con medidas de gobierno (organización del crédito agrícola, reforma de la Ley Hipotecaria, del Registro de la Propiedad y del Catastro, así como del fomento de la sindicación entre patronos y obreros)." BarRagán Moriana, A., Conflictividad social y desarticulación politica en la provincia de Córdoba, 1913-1920. Córdoba 1990. 240.

24 Asi, en su artículo aparecido en Andalucía durante los números de enero-abril de 1919. "Los latifundios en Andalucía", reproducción de páginas de su obra El ideal andaluz volvía a insistir en su machacona tesis sobre el papel obliterador de la institución para cualquier programa de reforma y renovación no solamente del campo sino de la vida andaluza toda. Insiste en ello Sevilla GuzMán, E., "Algunos precursores andaluces de la sociología rural. Segunda parte: Pascual Carrión y Blas Infante", Revista de Estudios Andaluces 4 (1985), 31-32. 
poránea. El abandono del lastre conservador aumentó las simpatías hacia el andalucismo en los círculos progresistas de la nación. Aunque sin llamarse a engaño sobre su fuerza, en los centros políticos del país y en algunos de sus órganos de prensa más influyentes comenzó a prestársele cierta atención a un andalucismo, que, aunque muy reducido en sus efectivos pequeñoburgueses - su única y permanente plataforma social-, creía haber pasado ya su etapa fundacional.

No era así. Una vez más los hechos conspiraron contra las ilusiones. En pleno impulso periodístico del andalucismo, Blas Infante intentó probar fortuna en el ruedo de la política nacional al integrar en las elecciones generales del otoño de 1919, junto a Alejandro Guichot e Isidoro Acevedo, la agrupación denominada "Democracia Andaluza». En el recuento de las urnas, Blas Infante ocupó el penúltimo lugar - 1.331 sufragios frente a los 10.015 del candidato más votado. Su dilatado arraigo y permanencia en la provincia encontró la recompensa de su victoria en el pueblo de Camas ${ }^{25}$.

${ }_{25}$ Ya en las del año 18 -confidenciaba don Rafael Castejón y Martínez de Arizala a su agudo entrevistador respecto a los resultados de los sufragios cordobeses en las elecciones parlamentarias de dicho año - "creíamos que habíamos interesado a la opinión, pero la realidad fue que en las elecciones de 1918 obtuvimos una miseria de votos". Memorias de Córdoba..., 55. 